\title{
Multi-Segment Linear Function Approximation to Nonlinear Shear Strength Envelope
}

\author{
X. Z. Lei, W. X. Fu ${ }^{1}$, and Y. Liao \\ State Key Laboratory of Hydraulic and Mountain River Engineering, Sichuan University, Chengdu, \\ China \\ ${ }^{1}$ wxf_lee@scu.edu.cn
}

УДК 539.4

\section{Аппроксимация нелинейной огибающей линии сдвиговой прочности с помощью мультисегментной линейной функции}

\author{
Кс. З. Леи, В. Кс. Фу, Й. Ляо \\ Сичуанский университет, Ченгду, Китай
}

\begin{abstract}
При подготовке инженерных проектов больиинство геотехнических специиалистов используют линейный критерий прочности Мора-Кулона вместо точного упругопластического решения Хоека-Брауна. Это обусловлено тем, что изменение наклона нелинейной огибающей линии сдвиговой прочности согласно решению Хоека-Брауна не может быть описано какимлибо одним линейным уравнением. Для аппроксимации этой линии используются мультисегментные линейные уравнения. Данная методика позволяет уменьшить погрешности при расчете в случае условного разбиения каждого материала на несколько зон, соответствующих истинному изменению градиента напряжений в материале. Для верификации предложенной методики выполнены расчеты погрешностей и сходимости результатов расчетов на конкретных примерах.
\end{abstract}

Ключевые слова: огибающая линия Хоека-Брауна, аппроксимация функции, погрешность аппроксимации, градиент напряжений.

Introduction. Practice of rock engineering projects has revealed that the shear strength of the in-situ rock mass has a non-linear feature. This feature is very significant under low stress levels. The Hoek-Brown (HB) criterion proposed by Hoek and Brown [1] can account for this observation. This criterion has been updated many times - see the paper by Hoek and Marinos [2]. Its most recent version is named the general HB criterion [3].

In spite of precise implementation made for the HB elasto-plastic analysis, e.g., Priest [4], Zhang [5], Fu and Liao [6], most geotechnical engineers and technicians usually choose the linear Mohr-Coulomb (MC) criterion for designs of engineering projects. In the HB elasto-plastic calculation, moreover, much iteration time needs being consumed when a failure stress state returns to the HB yield surface. The generalized HB criterion can evaluate the equivalent MC parameters [3]. Some researchers, e.g., Priest [7], Yang and Yin [8], Brown [9], also presented determining the MC parameters from the HB envelope. However, a particular linear $\mathrm{MC}$ equation cannot well match the curvature of a non-linear HB envelope. Moreover, when directly using the existing methods, there exist some difficulties in some situations, e.g., where there are two or more HB materials in the analytical model. 
In order to match the curvature variation of the non-linear HB envelope as closely as possible, this study employs multi-segment linear functions for its approximation. This paper gives the expressions for estimating the fitting error and for evaluating the equivalent MC strength parameters over an arbitrary stress interval. The fitting error analysis for three cases of equivalent $\mathrm{MC}$ fittings of the two materials in the slope example validates the present approximate description for the non-linear HB envelope. Moreover, the stability analysis for the slope shows that, when finely dividing the actual HB curve of each material, the results based on the multi-segment linear MC equations well agree with those obtained from the HB model.

1. Best-Fitting MC Equation for Non-Linear HB Envelope. The generalized HB criterion [6] in the $\sigma_{1}-\sigma_{3}$ plane is expressed in

$$
\sigma_{1}=\sigma_{3}+\sigma_{c i}\left(m_{b} \sigma_{3} / \sigma_{c i}+s\right)^{a}
$$

where

$$
\begin{gathered}
m_{b}=m_{i} e^{(G S I-100) /(28-14 D)}, \quad s=e^{(G S I-100) /(9-3 D)}, \\
a=1 / 2+\left(e^{-G S I / 15}-e^{-20 / 3}\right) / 6,
\end{gathered}
$$

$\sigma_{c i}$ is the uniaxial compressive strength of the intact rock specimen, $m_{i}$ is the material constant of the intact rock determined by the tri-axial compression testing, GSI is the abbreviation of the geological strength index, $D$ is the disturbance factor, and $\sigma_{1}$ and $\sigma_{3}$ are the major and minor principal stresses at failure, respectively (compressive stress is considered to be positive).

The $\sigma_{1}-\sigma_{3}$ relation of Eq. (1) is plotted in Fig. 1a. In this figure the two intersection points between the fitting MC line and HB curve are denoted by $B$ and $C$. The linear MC equation over the arbitrary stress interval of $\left[\sigma_{3 L}, \sigma_{3 U}\right]$ in Fig. 1a is expressed in

$$
\sigma_{1}=b+k \sigma_{3},
$$

where $k=\left(1+\sin \varphi_{e}\right) /\left(1-\sin \varphi_{e}\right), \quad b=2 c_{e} k^{1 / 2}$, and $\varphi_{e}$ and $c_{e}$ are the equivalent friction angle and cohesive force, respectively.

Using the best-fitting linear relation for approximating the non-linear HB envelope, i.e., the least-squares method, we derive the equations for estimating the fitting error and for evaluating the $\mathrm{MC}$ strength parameters over $\left[\sigma_{3 L}, \sigma_{3 U}\right]-$ see Appendix. The expressions of $\varphi_{e}$ and $c_{e}$ are

$$
\begin{gathered}
\varphi_{e}=\arcsin \left\{\frac{\frac{12 \sigma_{c i}^{2}}{m_{b}\left(\sigma_{3 U}-\sigma_{3 L}\right)^{3}}\left[\frac{\left(\sigma_{3 U}-\sigma_{3 L}\right)\left(u^{a+1}+l^{a+1}\right)}{2(a+1)}-\frac{\sigma_{c i}\left(u^{a+2}-l^{a+2}\right)}{m_{b}(a+1)(a+2)}\right]}{\left.2+\frac{12 \sigma_{c i}^{2}}{m_{b}\left(\sigma_{3 U}-\sigma_{3 L}\right)^{3}}\left[\frac{\left(\sigma_{3 U}-\sigma_{3 L}\right)\left(u^{a+1}+l^{a+1}\right)}{2(a+1)}-\frac{\sigma_{c i}\left(u^{a+2}-l^{a+2}\right)}{m_{b}(a+1)(a+2)}\right]\right\},}\right. \\
c_{e}=\left\{\frac{2 \sigma_{c i}^{2}\left(u^{a+1}-l^{a+1}\right)}{m_{b}(a+1)\left(\sigma_{3 U}-\sigma_{3 L}\right)}-\frac{12 \sigma_{c i}^{2}\left(\sigma_{3 U}+\sigma_{3 L}\right)}{m_{b}\left(\sigma_{3 U}-\sigma_{3 L}\right)^{3}} \times\right. \\
\left.\times\left[\frac{\left(\sigma_{3 U}-\sigma_{3 L}\right)\left(u^{a+1}+l^{a+1}\right)}{2(a+1)}-\frac{\sigma_{c i}\left(u^{a+2}-l^{a+2}\right)}{m_{b}(a+1)(a+2)}\right]\right\} \times
\end{gathered}
$$


$\times\left\{4\left\{1+\frac{12 \sigma_{c i}^{2}}{m_{b}\left(\sigma_{3 U}-\sigma_{3 L}\right)^{3}}\left[\frac{\left(\sigma_{3 U}-\sigma_{3 L}\right)\left(u^{a+1}+l^{a+1}\right)}{2(a+1)}-\frac{\sigma_{c i}\left(u^{a+2}-l^{a+2}\right)}{m_{b}(a+1)(a+2)}\right]\right\}^{1 / 2}\right\}^{-1}$,

where $u=m_{b} \sigma_{3 U} / \sigma_{c i}+s$ and $l=m_{b} \sigma_{3 L} / \sigma_{c i}+s$.

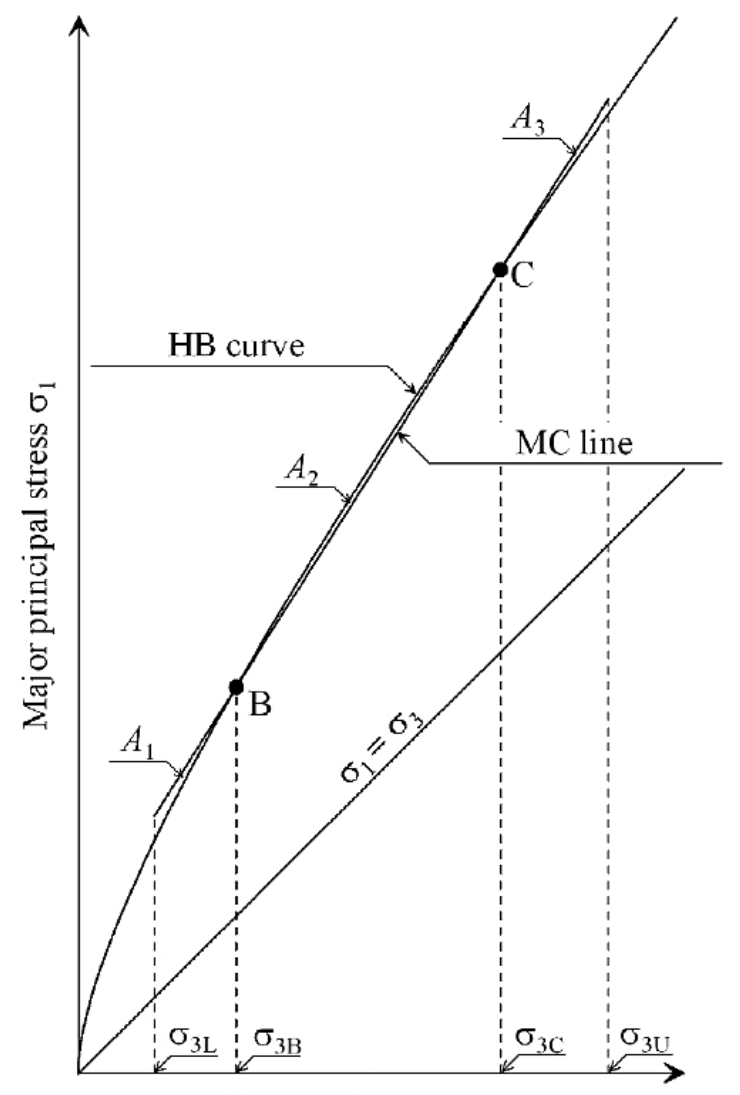

Minor principal stress $\sigma_{3}$

a

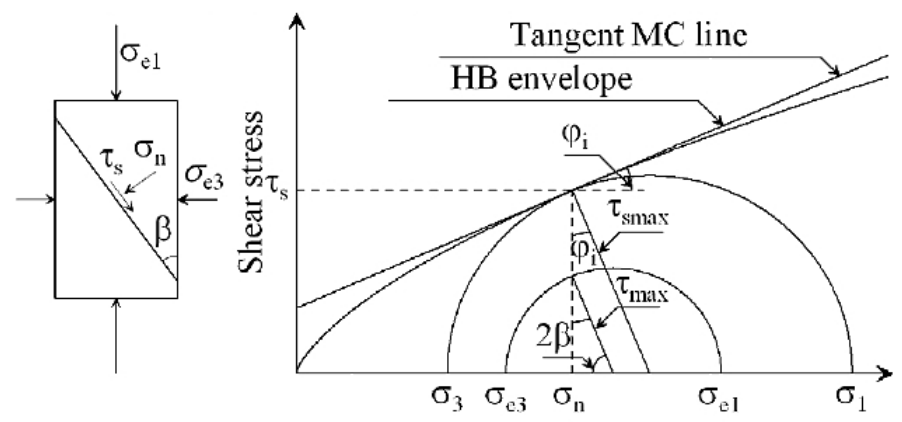

Normal stress

b

Fig. 1. Linear fitting for the HB curve over $\left[\sigma_{3 L}, \sigma_{3 U}\right]$ (a) and definition of the safety factor on the arbitrary section of a microunit (b). 
2. Multi-Segment Approximation to Non-Linear HB Envelope. It should be noted that the values of $\varphi_{e}$ and $c_{e}$ under different stress intervals, calculated by Eqs. (3) and (4), have obvious differences. If the specified stress range is too large, the shear strength under the low and high stress levels will be overestimated and that under the intermediate stress level will be underestimated.

In fact, the stress levels at different positions in each material (or even in a particular material) of the analytical model are different. Therefore, it is necessary to divide each material into different zones appropriate to the actual stress gradient variation of that material. Accordingly, the stress intervals chosen for different zones will yield a better agreement with the curvature variation of the HB envelope.

2.1. Determination of a Potential Failure Stress State. The minor principal stress employed for calculating $\varphi_{e}$ and $c_{e}$ in Eqs. (3) and (4) must be consistent with the stress state at failure. However, the stresses first calculated in the numerical analysis are the elastic solutions. In the elasto-plastic analysis, the stress path of any point in the numerical simulation model is very complicated and its possible position at the HB curve is unknown. Accordingly, the minor principal stress interval determined according to the elastic analysis cannot be directly used in Eqs. (3) and (4). Clearly, the interval of the minor principal stress at failure needs to be first determined.

As illustrated in Fig. 1b, any point in the numerical analytical model is treated as a microunit with one unit thickness. The principal stresses of the micro-unit, denoted by $\sigma_{e 1}$ and $\sigma_{e 3}$, respectively, can be determined by the elastic analysis. The corresponding stress circle and HB envelope are plotted in Fig. 1b. The principal stresses at failure, i.e., $\sigma_{1}$ and $\sigma_{3}$, will be determined in the following - see the massive stress group in Fig. 1b.

In the $\sigma_{1}-\sigma_{3}$ plane the slope of the tangent equation corresponding to any position on the HB curve can be easily derived:

$$
\frac{1+\sin \varphi_{i}}{1-\sin \varphi_{i}}=1+a m_{b}\left(\frac{m_{b} \sigma_{3}}{\sigma_{c i}}+s\right)^{a-1}
$$

where $\varphi_{i}$ is the instantaneous friction angle as illustrated in Fig. $1 b$.

Performing a simple transformation for Eq. (5) we can lead to

$$
\sigma_{3}=\frac{\sigma_{c i}}{m_{b}}\left[\frac{2 \sin \varphi_{i}}{a m_{b}\left(1-\sin \varphi_{i}\right)}\right]^{1 /(a-1)}-\frac{s \sigma_{c i}}{m_{b}} .
$$

Substituting Eq. (6) into Eq. (1) we attain

$$
\sigma_{1}=\frac{\sigma_{c i}}{m_{b}}\left[\frac{2 \sin \varphi_{i}}{a m_{b}\left(1-\sin \varphi_{i}\right)}\right]^{1 /(a-1)}-\frac{s \sigma_{c i}}{m_{b}}+\sigma_{c i}\left[\frac{2 \sin \varphi_{i}}{a m_{b}\left(1-\sin \varphi_{i}\right)}\right]^{a /(a-1)} .
$$

According to the relation between the massive stress circle and HB envelope in Fig. 1b, we can write the expressions of the normal and shear stresses denoted by $\sigma_{n}$ and $\tau_{s}$, respectively:

$$
\begin{gathered}
\sigma_{n}=\frac{\sigma_{1}+\sigma_{3}}{2}-\left[\frac{\sigma_{1}-\sigma_{3}}{2}\right] \sin \varphi_{i}, \\
\tau_{s}=\left[\frac{\sigma_{1}-\sigma_{3}}{2}\right] \cos \varphi_{i} .
\end{gathered}
$$


Substituting Eqs. (6) and (7) into Eqs. (8) and (9) we obtain

$$
\begin{gathered}
\sigma_{n}=\frac{\sigma_{c i}}{m_{b}}\left[\frac{2 \sin \varphi_{i}}{a m_{b}\left(1-\sin \varphi_{i}\right)}\right]^{1 /(a-1)}\left(\frac{\sin \varphi_{i}}{a}+1\right)-\frac{s \sigma_{c i}}{m_{b}}, \\
\tau_{s}=\frac{\sigma_{c i} \cos \varphi_{i}}{2}\left[\frac{2 \sin \varphi_{i}}{a m_{b}\left(1-\sin \varphi_{i}\right)}\right]^{a /(a-1)} .
\end{gathered}
$$

Observation for Fig. 1b shows that both of $\sigma_{n}$ and $\tau_{s}$ are monotonically-decreasing functions with respect to $\varphi_{i}$. The radius of the large stress circle in Fig. 1b, i.e., the maximum shear strength $\tau_{s \max }$, equals $\left(\sigma_{1}-\sigma_{3}\right) / 2$. Substituting Eqs. (6) and (7) into $\tau_{s \max }=\left(\sigma_{1}-\sigma_{3}\right) / 2$ we attain

$$
\tau_{s \max }=\frac{\sigma_{c i}}{2}\left[\frac{2 \sin \varphi_{i}}{a m_{b}\left(1-\sin \varphi_{i}\right)}\right]^{a /(a-1)} .
$$

The radius of the small stress circle in Fig. 1b, i.e., the maximum shear stress $\tau_{\text {max }}$, is

$$
\tau_{\max }=\frac{\sigma_{e 1}-\sigma_{e 3}}{2}
$$

Here we define the ratio of $\tau_{s \text { max }}$ to $\tau_{\max }$ as the safety factor $F_{s}$ of the microunit in Fig. 1b. Substituting Eqs. (12) and (13) into $F_{s}=\tau_{s \max } / \tau_{\max }$ we obtain

$$
F_{s}=\frac{\sigma_{c i}}{\left(\sigma_{e 1}-\sigma_{e 3}\right)}\left[\frac{2 \sin \varphi_{i}}{a m_{b}\left(1-\sin \varphi_{i}\right)}\right]^{a /(a-1)} .
$$

Equation (14) is a function with respect to $\sin \varphi_{i}$. When controlling the center position of the large stress circle in Fig. $1 \mathrm{~b}$ to be within the interval of $\left[\sigma_{e 3}, \sigma_{e 1}\right]$, we can find the value of $\sin \varphi_{i}$ corresponding to the minimum of $F_{S}$ by numerical iteration techniques, e.g., the Newton-Raphson method. When determining $\varphi_{i}$, we can calculate $\sigma_{n}$ and $\tau_{s}$ by Eqs. (10) and (11). Then we can determine $\sigma_{3}$ by Eq. (15), which is derived through a simple transformation for Eqs. (8) and (9)

$$
\sigma_{3}=\sigma_{n}-\frac{1-\sin \varphi_{i}}{\cos \varphi_{i}} \tau_{s}
$$

When determining $\varphi_{i}, \sigma_{n}$, and $\tau_{s}$, we can also calculate the instantaneous cohesive force $c_{i}$ by the $\sigma_{n}-\tau_{s}$ relation of the MC criterion, i.e., the equation as follows:

$$
c_{i}=\sigma_{n} \tan \varphi_{i}-\tau_{s} .
$$

2.2. Brief Description of the Application to the Analytical Model. A brief description for the application of the present method is given here. It is assumed that necessary material parameters, e.g., the Young modulus E, Poisson's ratio $v$, and bulk weight $\gamma$, have been input into the numerical analytical model and that all the boundary conditions have been correctly set. The initial estimate for the elastic stresses of each element can be first solved. 
The minor principal stress of each element at the potential failure state can be calculated by the above method. The interval of the minor principal stress at failure can be found by searching all elements of each material.

To agree with the curvature variation of each HB envelope under different stress levels as closely as possible, each material in the analytical model is divided into several zones. These zones can well match the actual stress variations at different positions of that material. When determining the interval of the minor principal stress at failure for each zone, one can calculate the corresponding MC parameters by Eqs. (3) and (4) and employ these parameters in the elasto-plastic analysis.

\section{Validity of the Approximate Description.}

3.1. Comparison of Fitting Error. To validate the present approximate description for the non-linear HB envelope, we first compare the fitting error for a simple slope with two materials. Figure 2a illustrates the sandstone and mudstone distributions and the slope geometrical dimensions. The basic material parameters are $\sigma_{c i}=30 \mathrm{MPa}, m_{i}=4, G S I=5$, $D=0, E=410 \mathrm{MPa}, v=0.3$, and $\gamma=25 \mathrm{kN} / \mathrm{m}^{3}$ for the sandstone, and $\sigma_{c i}=15 \mathrm{MPa}$, $m_{i}=2, G S I=5, D=0, E=290 \mathrm{MPa}, v=0.35$, and $\gamma=23 \mathrm{kN} / \mathrm{m}^{3}$ for the mudstone.

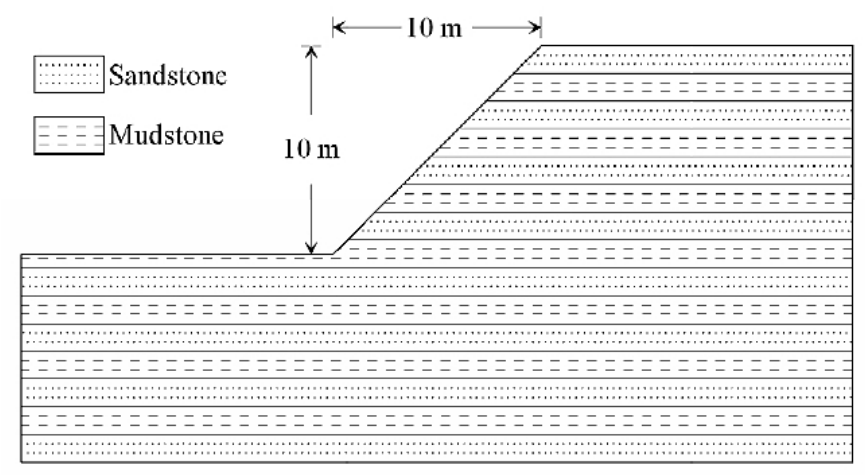

a

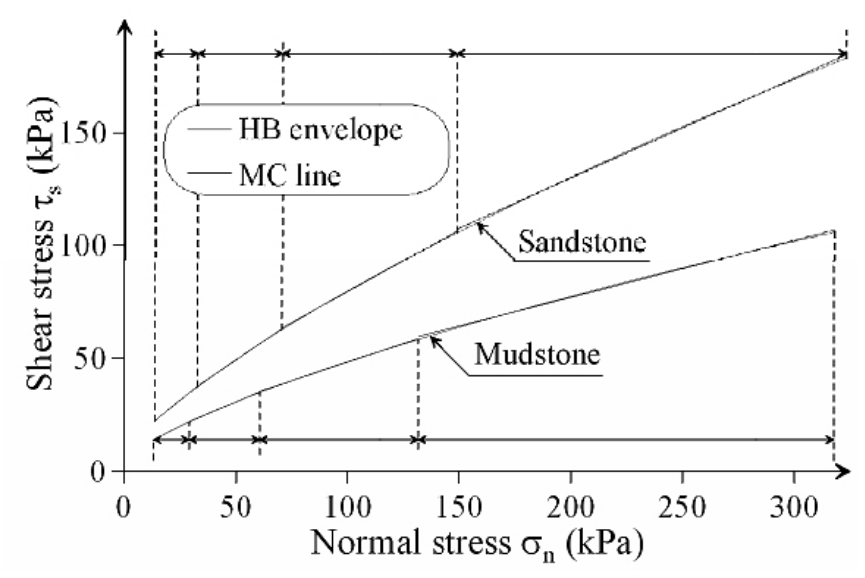

b

Fig. 2. Slope geometrical dimensions (a) and multi-segment approximations to the HB envelopes (b).

The elastic stress analysis was first performed for the slope model. Only the gravitational stress field was considered. The horizontal displacements with zero values were made for all nodes at the left- and right-hand side boundaries. The horizontal and 
vertical displacements were fixed to be zero values for all nodes at the bottom boundary. The actual $\sigma_{n}-\tau_{s}$ curves of the sandstone and mudstone are plotted in Fig. 2b.

Three cases of equivalent MC fittings were analyzed, referred to below as the cases I, II, and III. For the case I, the equivalent MC equations of each material were evaluated over the actual stress interval of that material; for the case II, each HB envelope was divided into two segments; and for the case III, each HB envelope was divided into four segments.

Here we only give the case III for example. As illustrated in Fig. 2b, the increment of the minor principal stress is unequal, while the absolute difference between the two instantaneous friction angles at the two end points of each segment is equal. Figure $2 b$ shows that the curvature variation of the HB curve can be well matched by use of an increasing step length for the increment of the minor principal stress.

The fitting error, i.e., the absolute error $\varepsilon_{\text {total }}$, over the actual stress interval of each material was also calculated for the three cases I, II, and III. The actual interval of the minor principal stress is [3.70, 199.09] in $\mathrm{kPa}$ for the sandstone and [5.03, 232.85] in $\mathrm{kPa}$ for the mudstone. For the case I, $\varepsilon_{\text {total }}$ equal 0.027691 for the sandstone and 0.009875 for the mudstone; for the case II, $\varepsilon_{\text {total }}$ equal 0.023599 for the sandstone and 0.008562 for the mudstone; and for the case III, $\varepsilon_{\text {total }}$ equal 0.021029 for the sandstone and 0.007600 for the mudstone. The results clearly indicate that the present method can reduce the fitting error when finely dividing each HB envelope. Comparatively, since the curvature of the mudstone envelope varies more obviously, the corresponding error decreases more significantly.

3.2. Further Discussion. To further validate the present method in the application to the stability calculation of slope, we implemented the elasto-plastic finite element method (FEM) analysis for the slope example by the shear strength reduction technique proposed by Zienkiewicz et al. [10], and the rigid body limit equilibrium analysis by the simplified Bishop method [11] as well. We also performed the HB elasto-plastic analysis referred to below as the case of iv for comparison.

In the HB elasto-plastic analysis, the HB envelope was described as a series of instantaneous equations and each element in the slope was assigned an MC equation [5]. In the MC elasto-plastic analysis, the corresponding parameters were evaluated by Eqs. (3) and (4). The shear strength was reduced by letting $\tan \varphi_{\text {trial }}=\tan \varphi_{e} / F_{\text {trial }}$ and $c_{\text {trial }}=$ $=c_{e} / F_{\text {trial }}$, where $F_{\text {trial }}$ is a reduction factor. The failure analysis was repeatedly performed by the bracketing approach, e.g., Dawson et al. [12], until the elasto-plastic solutions no longer converged.

In the limit equilibrium analysis by the simplified Bishop method, the HB model was applied to the slope as well. Accordingly, the instantaneous friction angle $\varphi_{i}$ at the base of a slice were determined by Eq. (10) in terms of the normal stress $\sigma_{n}$ acting on the base of each slice. Due to difficulties to write the explicit expression of $\varphi_{i}$, the Newton-Raphson method was employed for determining $\varphi_{i}$. Then the shear stress $\tau_{s}$ acting on the base of each slice was calculated by Eq. (11). In the limit equilibrium analysis by the simplified Bishop method, the MC model was also applied to the slope for comparison. Accordingly, the shear strength at the base of the slice was calculated by the $\sigma_{n}-\tau_{s}$ relation of the MC criterion.

The $F_{s}$-values under different cases are given in Table 1 . Observation for Table 1 shows that the $F_{S}$-value of each case obtained from the elasto-plastic FEM analysis is slightly less than that calculated by the simplified Bishop method. Also, when more finely dividing each HB envelope - as in the case III for example - the corresponding $F_{S}$-value more closely agrees with that determined in terms of the HB elasto-plastic analysis. Table 1 shows the same variations for the limit equilibrium analysis results by the simplified Bishop method. Moreover for the case of iii, the failure trend and slip zone based on the equivalent MC model closely agree with those obtained from the HB model - see Fig. 3. 
$\mathrm{T}$ a b 1 e 1

Safety Factor and Relative Error

\begin{tabular}{|c|c|c|c|c||}
\hline Case & FEM & $\left|F_{m L}-F_{h L}\right| F_{h L}, \%$ & Bishop method & $\left|F_{m B}-F_{h B}\right| F_{h B}, \%$ \\
\hline I & $F_{m L}=1.173$ & 8.210 & $F_{m B}=1.228$ & 7.155 \\
\hline II & $F_{m L}=1.103$ & 1.753 & $F_{m B}=1.166$ & 1.745 \\
\hline III & $F_{m L}=1.098$ & 1.292 & $F_{m B}=1.162$ & 1.396 \\
\hline IV & $F_{h L}=1.084$ & - & $F_{h B}=1.146$ & - \\
\hline
\end{tabular}
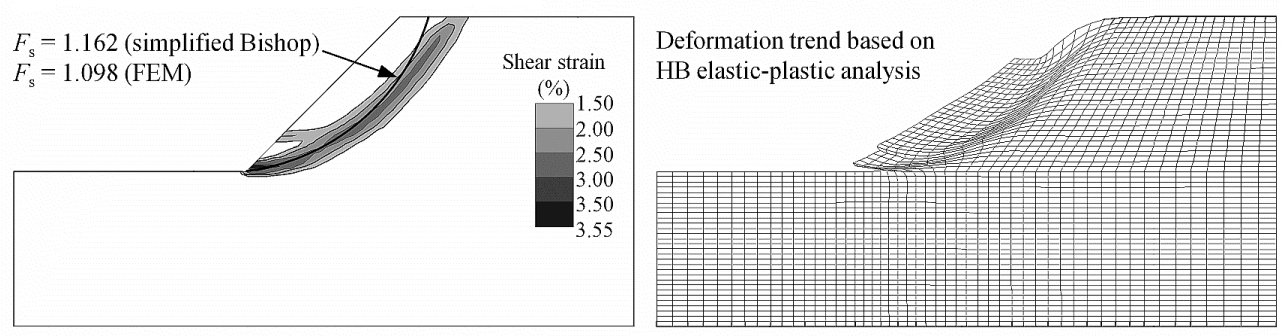

a
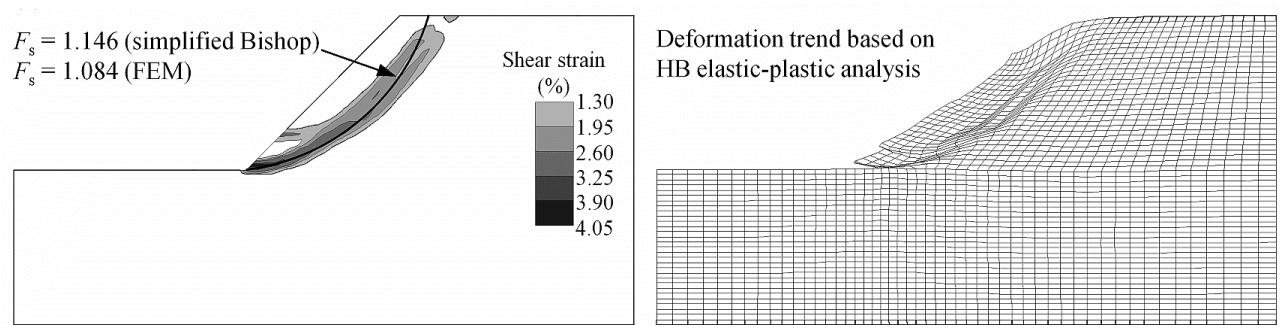

b

Fig. 3 Results for the cases III (a) and IV (b).

Conclusions. In this paper we propose the multi-segment linear equations for approximately describing the non-linear HB envelope. When dividing each material of the analytical mode into several zones appropriate to the actual stress gradient variation of that material, the present method can significantly reduce the error. Moreover, the comparison and analysis for the slope example have validated that, when more finely dividing the actual HB strength curve of each material, the safety factor and slip surface determined from the equivalent MC model more closely agree with those obtained from the HB model.

Acknowledgments. The present authors thank the National Nature Science Foundation of China (Grant No. 40972190) and the National Basic Science Foundation for the Sichuan University by the Ministry of Education of China (Grant No. 2010SCU23004) for financial supports. They thank the peer referees for good suggestions. They also thank Miss Zhe Li for polishing this paper.

\section{Appendix.}

Derivations for Eqs. (3) and (4). The HB curve is divided into three segments over $\left[\sigma_{3 L}, \sigma_{3 U}\right]$ as illustrated in Fig. 1a. The three parts of areas between the MC line and HB curve, i.e., $A_{1}, A_{2}$, and $A_{3}$ in Fig. 1a, can be found by integration.

Using the state to equalize the areas above and below the MC line, i.e., $A_{1}+A_{3}=A_{2}$, we can write the expression as follows: 


$$
\int_{\sigma_{3 L}}^{\sigma_{3 U}}\left[b+(k-1) \sigma_{3}\right] d \sigma_{3}-\int_{\sigma_{3 L}}^{\sigma_{3 U}} \sigma_{c i}\left(m_{b} \sigma_{3} / \sigma_{c i}+s\right)^{a} d \sigma_{3}=0 .
$$

The explicit expression of Eq. (A1) is

$$
2 b+(k-1)\left(\sigma_{3 U}+\sigma_{3 L}\right)=t,
$$

where

$$
t=\frac{2 \sigma_{c i}^{2}\left(u^{a+1}-l^{a+1}\right)}{m_{b}(a+1)\left(\sigma_{3 U}-\sigma_{3 L}\right)},
$$

and the definitions of $u$ and $l$ in Eq. (A3) have been given in Eqs. (3) and (4).

We can decompose Eq. (A3) as

$$
\begin{aligned}
& b+(k-1) \sigma_{3 U}=\frac{t+(k-1)\left(\sigma_{3 U}-\sigma_{3 L}\right)}{2}, \\
& b+(k-1) \sigma_{3 L}=\frac{t-(k-1)\left(\sigma_{3 U}-\sigma_{3 L}\right)}{2} .
\end{aligned}
$$

For any $\sigma_{3}$ within the interval of $\left[\sigma_{3 L}, \sigma_{3 U}\right]$, the squared error between the MC line and $\mathrm{HB}$ curve is defined by

$$
\varepsilon\left(\sigma_{3}\right)^{2}=\left[\left(b+k \sigma_{3}\right)-\sigma_{3}-\sigma_{c i}\left(m_{b} \sigma_{3} / \sigma_{c i}+s\right)^{a}\right]^{2} .
$$

The total squared error over $\left[\sigma_{3 L}, \sigma_{3 U}\right]$ is

$$
\begin{gathered}
\varepsilon_{\text {total }}=\int_{\sigma_{3 L}}^{\sigma_{3 U}} \varepsilon\left(\sigma_{3}\right)^{2} d \sigma_{3}=\int_{\sigma_{3 L}}^{\sigma_{3 U}}\left[(k-1) \sigma_{3}+b\right]^{2} d \sigma_{3}- \\
-\int_{\sigma_{3 L}}^{\sigma_{3 U}} 2 \sigma_{c i}\left[(k-1) \sigma_{3}+b\right]\left(m_{b} \sigma_{3} / \sigma_{c i}+s\right)^{a} d \sigma_{3}+\int_{\sigma_{3 L}}^{\sigma_{3 U}} \sigma_{c i}^{2}\left(m_{b} \sigma_{3} / \sigma_{c i}+s\right)^{2 a} d \sigma_{3} .
\end{gathered}
$$

The explicit expression of $\varepsilon_{\text {total }}$ is

$$
\begin{gathered}
\varepsilon_{\text {total }}=\frac{\left(\sigma_{3 U}-\sigma_{3 L}\right)}{3}\left\{t^{2}-\frac{t^{2}-(k-1)^{2}\left(\sigma_{3 U}-\sigma_{3 L}\right)^{2}}{4}\right\}- \\
-\frac{2 \sigma_{c i}^{2}}{m_{b}}\left\{\frac{\left[t+(k-1)\left(\sigma_{3 U}-\sigma_{3 L}\right)\right] u^{a+1}}{2(a+1)}-\frac{\left[t-(k-1)\left(\sigma_{3 U}-\sigma_{3 L}\right)\right] l^{a+1}}{2(a+1)}-\right. \\
\left.-\frac{\sigma_{c i}(k-1)\left(u^{a+2}-l^{a+2}\right)}{m_{b}(a+1)(a+2)}\right\}+\frac{\sigma_{c i}^{3}\left(u^{2 a+1}-l^{2 a+1}\right)}{m_{b}(2 a+1)} .
\end{gathered}
$$


When considering Eq. (A8) as a function with respect to $k$, we can write the first-order derivative of $\varepsilon_{\text {total }}$ with respect to $k$ :

$$
\begin{gathered}
\varepsilon_{\text {total }}^{\prime}=\frac{\left(\sigma_{3 U}-\sigma_{3 L}\right)^{3}(k-1)}{6}- \\
-\frac{2 \sigma_{c i}^{2}}{m_{b}}\left[\frac{\left(\sigma_{3 U}-\sigma_{3 L}\right)\left(u^{a+1}+l^{a+1}\right)}{2(a+1)}-\frac{\sigma_{c i}\left(u^{a+2}-l^{a+2}\right)}{m_{b}(a+1)(a+2)}\right] .
\end{gathered}
$$

According to the condition of minimizing $\varepsilon_{\text {total }}$, i.e., $\varepsilon_{\text {total }}^{\prime}=0$, we lead to

$$
k=1+\frac{12 \sigma_{c i}^{2}}{m_{b}\left(\sigma_{3 U}-\sigma_{3 L}\right)^{3}}\left[\frac{\left(\sigma_{3 U}-\sigma_{3 L}\right)\left(u^{a+1}+l^{a+1}\right)}{2(a+1)}-\frac{\sigma_{c i}\left(u^{a+2}-l^{a+2}\right)}{m_{b}(a+1)(a+2)}\right] .
$$

Substituting Eq. (A10) into $k=\left(1+\sin \varphi_{e}\right) /\left(1-\sin \varphi_{e}\right)$ we obtain Eq. (3), and substituting $b$ of Eq. (A2) and $k$ of Eq. (A10) into $b=2 c_{e} k^{1 / 2}$ we obtain Eq. (4).

\section{Резюме}

При підготовці інженерних проектів більшість геотехнічних фахівців використовують лінійний критерій міцності Мора-Кулона замість пружно-пластичного розв'язку Хоека-Брауна. Це зумовлено тим, що зміна нахилу нелінійної обвідної лінії зсувної міцності згідно з розв'язком Хоека-Брауна не може бути описана будь-яким одним лінійним рівнянням. Для апроксимації цієї лінії використовуються мультисегментні лінійні рівняння. Дана методика дозволяє зменшити похибки при розрахунках у випадку умовного розбиття кожного матеріалу на декілька зон, що відповідають істинній зміні градієнта напружень у матеріалі. Для верифікації запропонованої методики оцінено похибки і збіжність результатів розрахунків на конкретних прикладах.

1. E. Hoek and E. T. Brown, "Empirical strength criterion for rock masses," J. Geotech. Engng. Div., 106, No. GT9, 1013-1035 (1980).

2. E. Hoek and P. Marinos, "A brief history of the development of the Hoek-Brown failure criterion," Soils and Rocks, 30, No. 2, 85-92 (2007).

3. E. Hoek, C. Carranza-Torres, and B. Corkum, "Hoek-Brown failure criterion - 2002 edition," in: R. Hammah (Ed.), NARMS-TAC 2002: Mining and Tunnelling Innovation and Opportunity (Proc. of the 5th North American Rock Mechanics Symposium and the 17th Tunnelling Association of Canada Conference: NARMS-TAC 2002, July 7-10, 2002, Toronto, Ontario, Canada), Vol. 1, University of Toronto Press (2002), pp. 267-273.

4. S. D. Priest, "Comparisons between selected three-dimensional yield criteria applied to rock," Rock Mech. Rock Eng., 43, No. 4, 379-389 (2010).

5. L. Zhang, "A generalized three-dimensional Hoek-Brown strength criterion," Rock Mech. Rock Eng., 41, No. 6, 893-915 (2008).

6. W. X. Fu and Y. Liao, "Non-linear shear strength reduction technique in slope stability calculation," Comput. Geotech., 37, 288-298 (2010).

7. S. D. Priest, "Determination of shear strength and three-dimensional yield strength for the Hoek-Brown criterion," Rock Mech. Rock Eng., 38, No. 4, 299-327 (2005). 
8. X. L. Yang and J. H. Yin, "Slope equivalent Mohr-Coulomb strength parameters for rock masses satisfying the Hoek-Brown criterion," Rock Mech. Rock Eng., 43, No. 4, 505-511 (2010).

9. E. T. Brown, "Estimating the mechanical properties of rock masses," in: Y. Potvin, J. Carter, A. Dyskin, and R. Jeffrey (Eds.), Proceedings of the First Southern Hemisphere International Rock Mechanics Symposium (SHIRMS 2008, Sept. 16-19, 2008, Perth, Western Australia), Vol. 1, Australian Centre for Geomechanics (2008), pp. 3-21.

10. O. C. Zienkiewicz, C. Humpheson, and R. W. Lewis, "Associated and nonassociated viscoplasticity in soil mechanics," Géotechnique, 25, No. 4, 671-689 (1975).

11. A. W. Bishop, "The use of the slip circle in the stability analysis of slopes," Géotechnique, 5, No. 1, 7-17 (1955).

12. E. M. Dawson, W. H. Roth, and A. Drescher, "Slope stability analysis by strength reduction," Géotechnique, 49, No. 6, 835-840 (1999).

Received 15. 01. 2015 